\title{
ПСИХОЛОГИЧЕСКИЕ РЕСУРСЫ ПРЕОДОЛЕНИЯ СТРЕССА СУБЪЕКТАМИ КОМАНДНОЙ ДЕЯТЕЛЬНОСТИ
}

Совмиз 3.Р. (Кубанский государственный университет физической культуры, спорта и туризма, Краснодар, Россия) zarema83888@yandex.ru

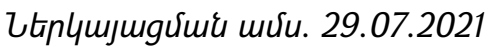

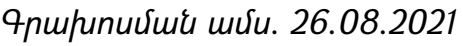

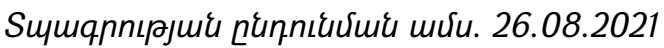

В данной статье рассматриваются особенности включения личности в индивидуальный и командный копинг. В исследовании выявлены особенности соотношения индивидуальных и командных копингстратегий субъектов командной деятельности; личностные и групповые копинг-ресурсы; ограничители успешного преодоления стресса; опосредованная взаимосвязь личностных ресурсов с копинг-стратегиями, посредником которой являются групповые ресурсы; специфичность спортивной деятельности; типы реагирования субъектов командной деятельности на стресс. Полученные данные позволяют прогнозировать успешность преодоления стресса субъектами совместной деятельности.

Ключевые слова: субъект командной деятельности, индивидуальные и командные копинг-стратегии, личностные и групповые копинг-ресурсы.

DOI: https://doi.org/10.46991/SBMP/2021.4.2.323

Введение. Постоянно растущее внимание исследователей к проблематике преодоления человеком стресса открывает новые горизонты в изучении данной темы. К новым исследовательским виткам в ее рамках относится анализ поведения личности в трудной ситуации с учетом включения ее в данный процесс как индивидуальности и как субъекта командной деятельности, т.е. с применением индивидуальных и командных копинг-стратегий. Стоит отметить, что проблема индивидуальных стратегий преодоления стресса является более разработанной, в то время как исследования командного копинга ограничиваются анализом семей, бизнес-групп и макро-групп [1; 2]. За пределами внимания исследователей оказывается изучение множества малых групп, деятельность которых сопровождается фракторами высокого уровня стрессогенности. В связи со слабой изученностью проблемы включения личности в командный копинг, остается открытым вопрос об особенностях применения психологических ресурсов, детерминирующих успешность индивидуального и командного копинг-поведения.

В своем исследовании мы сконцентрировались на копинг-активности спортсменов командных видов спорта, так как рассматриваем спортивные 
команды как яркую модель включения личности в преодоление стресса как индивидуальности и как субъекта командной деятельности, позволяющую раскрыть специфику регуляции копинг-механизмов. Стрессы, связанные с обязательностью соревнований и остротой конкуренции, неотъемлемое условие деятельности спортсменов, которое актуализирует необходимость овладения навыками применения адаптивных копингов [3; 4].

Цель исследования - выявление психологических ресурсов индивидуальных и командных копинг-стратегий субъектов командной деятельности на примере спортивных команд как ярких представителей стрессогенных условий труда.

Выборка исследования: 76 спортсменов высокой квалификации, представляющих команды по футболу, гандболу, баскетболу и регби.

Исследование субъектов командной деятельности проводилось в трех направлениях: 1) изучение особенностей применяемых ими копинг-стратегий; 2) анализ их личностных параметров: эмоционального и социального интеллекта, коммуникативных и организаторских способностей, мотивации достижения успехов и избегания неудач, готовности к риску, социальнопсихологической адаптации, психосоциальной зрелости, восприятия спортсменом поддержки автономии со стороны тренера, стилей поведения в конфликте; 3) изучение социально-психологических характеристик групп, в состав которых они входят: психологической атмосферы, групповой мотивации, сплоченности, уровня развития группы. Примененные методы психодиагностики и математической статистики подробно отражены в статье, опубликованной ранее [5].

Обсуждение результатов. Первоначальной задачей исследования было выявление выраженности адаптивных и неадаптивных копинг-стратегий субъектов командной деятельности. Установлено, что уровень развития индивидуальных адаптивных копингов равен 78,8 балла, индивидуальных дезадаптивных - 48,4 балла, командных адаптивных - 71,8 балла, командных дезадаптивных - 55,2 балла; командных дисфункциональных и деструктивных - 52,1 балла. Полученные данные отражают благоприятную картину, так как конструктивные копинги развиты высоко и преобладают над неконструктивными. При этом командные адаптивные копинги ниже по уровню развития, чем адаптивные индивидуальные. Это свидетельствует о более сложном процессе их становления и меньшей вероятности полноценного применения субъектами командной деятельности.

Согласно следующей задаче исследования, которая состояла в выявлении взаимосвязи копинг-стратегий с личностными параметрами, было установлено три группы личностных ресурсов, по-разному влияющих на процесс регуляции копинг-стратегий. Первая группа: максимально ресурсные характеристики, 
укрепляющие вероятность применения конструктивных копингов и уменьшающие вероятность выбора неконструктивных (эмоциональный интеллект, психосоциальная зрелость, мотивация достижения, организаторские способности, интегральные компоненты социально-психологической адаптации). Вторая группа ресурсов, представленная в виде коммуникативных способностей и поддержки автономии спортсмена тренером, характеризуется направленностью лишь на укрепление адаптивных копингов. К третьей группе личностных ресурсов относятся характеристики, направленные только на снижение вероятности применения дезадаптивных копингов, т.е. проявляющие взаимосвязь лишь с неконструктивными стратегиями совладания. К ней относится композитная оценка социального интеллекта, чувствительность к характеру межличностных взаимоотношений, умение распознавать структуру межличностных ситуаций в динамике, проникающая способность в эмпатии, конструктивные компоненты социально-психологической адаптации (самопринятие, эмоциональный комфорт, доминирование). Помимо ресурсных параметров нами выявлены характеристики, выступающие в качестве ограничителей эфффективного преодоления стресса. К ним относятся чрезмерно высокие показатели рационального и эмоционального каналов эмпатии, которые повышают дезадаптивные копинги; умение анализировать сложные ситуации взаимодействия, которое снижает адаптивные; неконструктивные компоненты социально-психологической адаптации, которые взаимодействуют с копингами в обоих указанных направлениях. Стрессогенность спорта делает чрезмерную эмпатичность источником дополнительных психологических нагрузок, снижающих конструктивность копинг-поведения. Стоит учитывать и специфику спорта, требующую от спортсменов мобильности в принятии решений. Высокоразвитое умение анализировать сложные ситуации взаимодействия предоставляет множество различных ходов в стрессе. При этом время, затраченное на выбор более эффективного действия, в условиях дефрицита времени, приводит к снижению степени конструктивности примененного копинга, актуального в контексте той или иной ситуации.

В спектре групповых копинг-ресурсов наиболее продуктивным показателем является сплоченность, так как укрепляет адаптивные копинги и снижает вероятность применения командных дезадаптивных. Остальные групповые характеристики (атмосфера, уровень развития группы, групповая мотивация) являются ресурсом лишь по укреплению адаптивных копингов.

В процессе исследования было выявлено, что личностные параметры могут быть ресурсами копинг-стратегий, коррелируя с ними не только напрямую, но и опосредованно, через взаимосвязь с групповыми. Личностные характеристики спортсменов в виде внутриличностного эмоционального интеллекта, коммуникативных способностей, готовности к риску, сотрудничества в 
конфрликте, зрелости и адаптивности вносят наибольший вклад в успешное развитие социально-психологических параметров команды. Убеждение в том, что преодоление стресса сложный и многогранный процесс, в котором возможны различные комбинации копинг-ресурсов, привело нас к необходимости выявления индивидуальных типов реагирования субъектов командой деятельности на стресс. Благодаря процедуре кластеризации выборка разделилась на четыре группы, различающиеся по соотношению адаптивных и неадаптивных копингов, дифференцированности копинг-ресурсов и интенсивности их вовлечения в борьбу со стрессом. Кластерам были присвоены наименования с учетом выявленных различий: «высоко адаптивный, экономичный» (А); «умеренно адаптивный, ресурсно дифференцированный» (B); «неустойчиво адаптивный, ресурсно затратный» (C); «умеренно адаптивный, ресурсно недиффреренцированный» (D). Сравнительный анализ копинг-стратегий в кластерах показал, что наибольшими различиями характеризуются «высоко адаптивный, экономичный кластер» (А) и «неустойчиво адаптивный, ресурсно затратный» (С) (таблица 1).

Кластер «высоко адаптивный, экономичный» (A) обладает наиболее высокими показателями в развитии большинства личностных и групповых параметров в сочетании с низким уровнем развития неконструктивных компонентов адаптации и умеренным, т.е. наиболее благоприятным, уровнем эмпатии. В данном кластере прослеживается четкое разделение и экономное применение ресурсов, реализующих индивидуальные и командные копинги.

Таблица 1.

Медианы показателей копинг-стратегий в четырех кластерах субъектов командной деятельности (в баллах)

\begin{tabular}{|l|c|c|c|c|c|c|c|c|c|}
\hline \multirow{2}{*}{$\begin{array}{l}\text { Копинг- } \\
\text { стратегии }\end{array}$} & \multicolumn{5}{|c|}{ Кластеры } & \multicolumn{5}{c|}{ Достоверность различий } \\
\cline { 2 - 10 } & $\begin{array}{c}\mathrm{A}=7) \\
(\mathrm{n}=17)\end{array}$ & $\begin{array}{c}\mathrm{B}=24) \\
(\mathrm{n}=1 \mathrm{n}=28)\end{array}$ & $\mathrm{A} / \mathrm{B}$ & $\mathrm{A} / \mathrm{C}$ & $\mathrm{A} / \mathrm{D}$ & $\mathrm{C} / \mathrm{B}$ & $\mathrm{C} / \mathrm{D}$ \\
\hline $\begin{array}{l}\text { индивидуальные } \\
\text { адаптивные }\end{array}$ & 89 & 75 & 73 & 78 & $\mathrm{p} \leq 0,05$ & $\mathrm{p} \leq 0,05$ & $\mathrm{p} \leq 0,05$ & - & $\mathrm{p} \leq 0,05$ \\
\hline $\begin{array}{l}\text { индивидуальные } \\
\text { дезадаптивные }\end{array}$ & 35 & 40 & 56 & 45,5 & - & $\mathrm{p} \leq 0,05$ & $\mathrm{p} \leq 0,05$ & $\mathrm{p} \leq 0,05$ & - \\
\hline $\begin{array}{l}\text { командные } \\
\text { адаптивные }\end{array}$ & 76 & 71 & 66 & 73,5 & - & $\mathrm{p} \leq 0,05$ & - & - & $\mathrm{p} \leq 0,05$ \\
\hline $\begin{array}{l}\text { командные } \\
\text { дезадаптивные }\end{array}$ & 33 & 56 & 60,5 & 54 & $\mathrm{p} \leq 0,05$ & $\mathrm{p} \leq 0,05$ & $\mathrm{p} \leq 0,05$ & - & - \\
\hline $\begin{array}{l}\text { командные } \\
\text { дисфункциональ } \\
\text { ные, } \\
\text { деструктивные }\end{array}$ & 32 & 49 & 59,5 & 50 & - & $\mathrm{p} \leq 0,05$ & $\mathrm{p} \leq 0,05$ & $\mathrm{p} \leq 0,05$ & $\mathrm{p} \leq 0,05$ \\
\hline
\end{tabular}


Самопринятие и принятие других снижает вероятность применения индивидуальных адаптивных копингов, в то время как непринятие себя повышает. Возможно, это связано с тем, что данный кластер составили более зрелые спортсмены, а значит более самодостаточные и уверенные в себе. Чем больше они удовлетворены собой и окружающими, тем ниже стремление к применению индивидуальных копингов. Противоположным данному кластеру является наименее успешный в преодолении стресса кластер «неустойчиво адаптивный, ресурсно затратный» (С) (таблица 1). Все личностные и групповые параметры развиты в нем ниже. В борьбу со стрессом вовлекается широкий спектр ресурсов, отсутствует их четкая дифференциация. В рамках данного кластера ярко прослеживается роль личностных свойств как копинг-ресурсов субъектов командной деятельности обусловленная спецификой деятельности, в которую включена группа. В данном случае, соревновательная суть спорта, межгрупповое и внутригрупповое соперничество в командах проявляется в снижении вероятности применения конструктивных командных копингов при высоких показателях самопринятия. Подобная картина проявляется и при высоком уровне самодетерминации, что видно в кластере "умеренно адаптивный, ресурсно диффференцированный» В.

Таким образом, преодоление стресса субъектами командной деятельности возможно за счет различных сочетаний личностных и групповых ресурсов, обеспечивающих различную степень конструктивности копинг-поведения. Уровень дифференцированности психологических ресурсов индивидуальных и командных копинг-стратегий является предпосылкой $k$ успешному преодолению стресса субъектами командной деятельности.

Анализ реальных групп (спортивных команд) С точки зрения представительства в них различных кластеров, показал, что наибольшие различия проявляются между мужскими командами по гандболу и баскетболу. В команде по гандболу наименьшее количество субъектов менее успешного кластера «неустойчиво адаптивный, ресурсно затратный» (C) - 13\%. Остальные кластеры представлены в данной команде в следующем процентном соотношении: В - 47\%; A - 13\%; D - 27\%. Команду по баскетболу, наоборот, в большей степени составляют представители кластера (C) - 67\%; кластер A - 11\%; D - 22\%. Данные команды отличаются по уровню развития личностных ресурсов (эмоциональный интеллект, коммуникативные и организаторские способности, психосоциальная зрелость, социально-психологическая адаптация) в пользу команды по гандболу, но не имеют различий по уровню групповых. Спортсмены команды по гандболу предпочитают командные копинги, а команды по баскетболу - индивидуальные. В команде по гандболу наиболее сильным копинг-ресурсом выступают все исследованные социальнопсихологические параметры и личностные характеристики в виде зрелости, 
эмоционального интеллекта, конструктивных компонентов адаптации, установок, способствующих эмпатии, проникающей способности в эмпатии, понимания логики развития ситуаций. В команде по баскетболу групповые параметры являются более слабым ресурсом. А в качестве личностных копингресурсов выступают эмоциональный интеллект, социально-психологическая адаптация (в частности принятие других), идентификация в эмпатии, коммуникативные склонности, избегание конфликта, психологическая защита.

Таким образом, особенности копинг-стратегий групповых субъектов обусловлены специфичным для каждой команды сочетанием включенных в нее индивидуальных субъектов, располагающих в большей или меньшей степени ресурсами конструктивного преодоления стресса.

Полученные данные вносят новые представления об особенностях развития личностных и групповых копинг-ресурсов субъектов командной деятельности, показывают неоднозначность в их проявлении; об индивидуальных вариантах регуляции копингов в реальных группах; обращают внимание на специфичность условий спортивной деятельности в преодолении стресса личностью как субъектом индивидуального и командного копинга.

\section{Литература}

1. Белинская Е. П., Икрамова А. А. Взаимосвязь совместного копинга и уровня групповой сплоченности при выработке группового решения // Вестник Кемеровского государственного университета. 2015. № 3 (63) T. 3. с. 82-87.

2. Крюкова Т. Л., Сапоровская М. В. Стрессы семейных отношений: тенденции и эфффекты совладания // Институт психологии Российской академии наук. Социальная и экономическая психология. 2016. Т. 1. № 1. с. 174-195.

3. Горская Г. Б. Организационный стресс в спорте: источники, специфика проявлений, направления исследований // Физическая культура, спорт - наука и практика. 2012. № 4. с. 74-76.

4. Kerdijk C., van der Kamp J., Polman R. C. J. The Influence of the Social Environment Context in Stress and Coping in Sport // Frontiers in Psychology, 2016. № 7, p. 875.

5. Совмиз 3. Р. Личностные регуляторы стратегий преодоления стресса субъектами групповой деятельности // Человек. Сообщество. Управление. Краснодар. 2016. Т. 17. №4. С.138-152. 


\section{PSYCHOLOGICAL RESOURCES OF STRESS COPING SUBJECTS OF TEAM ACTIVITIES}

Sovmiz Z.R. (Kuban State University of Physical Culture, Sports and Tourism, Krasnodar, Russia)

This article discusses the features of inclusion of personality in individual and team coping. The study revealed the features of correlation of individual and team coping strategies of the subjects of team activities; individual and group coping resources; constraints to successful coping with stress; indirect inter-relation of individual resources with coping strategies group activity where the intermediary is group resources; specificity of athletic activities; reaction types of actors (group activity) on how they respond to stress. Obtained data allow to forecast the success rate of actors of team activity in the process of stress coping.

Keywords: subject of team activity, individual and group coping-strategies, individual and group coping-resources. 